\title{
University Medical Staff Perception Towards Using Electronic Information Resources
}

\author{
Ayman S. Abdelhady \\ Public Health Department -Faculty of Medicine, Al-Azhar University \\ ( Assuit branch).
}

\begin{abstract}
University staff are increasingly expected to use electronic resources of information. Studies were undertaken to determine the level of use of this type of resources and how university staff feel about various issues surrounding the use of these resources.

A random sample of one hundred (100) university medical staff (academic and clinical), Al-Azhar University, completed questionnaire to determine the level of use of various electronic information resources, if they perceived themselves capable of using these resources and the various methods employed to acquire skills necessary to use such resources. A wide variety of views were expressed by the sample staff but the main findings suggested that the most common electronic resources of information used by the staff were CD-Roms and the internet as $72 \%$ and $63 \%$ respectively. Also, the study suggested that faster access to information was noted as a main advantage of using these resources where detected by $67 \%$ of the staff members and $62 \%$ showed that these resources allowed a wider range of information. The study also showed that the staff had the ability to utilize these resources and obtain information from the internet whenever they want, in spite of some barriers of use, detected in the study and found to be facing the staff which were mostly limited time and lack of retrieval skills of information from these resources. The most popular methods of acquiring the necessary skills to use electronic resources were via guidance from other peers and courses offered by the university. Furthermore, researches were necessary to show how best to encourage staff and students to make effective use of electronic sources that are available.
\end{abstract}

\section{Introduction}

The last few years have seen a number of changes in the higher education sector which have exerted pressure upon the traditional role of the academic library, changes in teaching and learning methods, towards a greater emphasis on student centred learning growing number of academic publications, inflation in the cost of printed materials and technological developments. This latter change, with increased amount of the available electronic resources, resulted in a demand for information skills training for both staff and students (Bawden, 1990).

These skills include a knowledge of the structure of the database and the instructions which must be input into the computer by the searcher, as well as an understanding of the way in which the instructions are linked with one another
(Blum, 1986). Furthermore, Brophy (1993) stated that users don not often appreciate the skills required to search these sources, the ability to find and retrieve information effectively in a transferable skills useful for future life as well as enabling the positive and successful use of the electronic resources whilst at university.

Dutton (1990) and Blandy \& Libutti (1995) suggested that the skills required to maximize the potential of electronic resources are much greater than those required for searching printed sources.

Brophy (1993) detailed the advantages of the networking for the user as being, the information needed can be delivered from the most appropriate source to the user, the user can re-specify his or her need dynamically, the information is obtained when it is wanted, electronic information 


\section{Ayman S. Abdelhady}

can therefore provide a number of advantages over traditional print based sources.

These advantages include the fact that electronic information sources are often faster than consulting print indices, especially when searching retrospectively and they are more straight forward when wishing to use combination of keywords. They open up the possibility of searching multiple files at one time. Universities use considerable proportion of their budget to provide this technology for their staff and students to assist in the learning process (Shortliffe and Perreault, 1996). How do students and staff themselves feel about the availability of electronic information, which may require the acquisition of new skills to utilize it effectively?

This paper aimed to contribute to the limited information resources and to determine the level of use of this type of resources.

\section{Methodology}

-The staff members of Al- Azhar faculty of medicine in Cairo, were estimated to be 972 members during 2001.

-The sample size was calculated by using Epi Info version 2001 computer program ,with worst acceptable percentage of 0.05 and confidence level of $99.9 \%$, where the sample size was estimated to be 87 medical staff members.

-A number of one hundred (100) medical staff (academic and clinical) was chosen by the stratified random method to cover this minimal sample size.

-A number of self administered questionnaires was distributed to the selected medical staff, during September 2002 , where staff opinions towards the use of electronic resources were collected including :

*The use and types of electronic information resources.

*Access to a networked computer at university or at home and the most popular electronic resources (CD-Roms, internet and electronic journals).
*How respondents feel electronic resources, whether respondents avoid electronic sources due to inability to use them and the benefits as well as the barriers of using these electronic sources.

-Staff views on various aspects were assessed by items mainly of the Likert type. Such those responders indicated their opinion by encircling one of the following (strongly agree, agree, I don't know, disagree, or strongly disagree). Negative and positive statements were randomly distributed to avoid response bias. Data management was conducted through IBM personal computer with EPI-5 Info package.

\section{Results}

The most popular electronic information sources used by the sample were CD-Roms (72\%) and the internet with (63\%) followed by electronic journals (27\%) (Table 1).

The most popular methods of acquiring the necessary skills to use electronic resources were via guidance form other peers $(72 \%)$ and courses offered by university or collage $(61 \%)$. More than half of the respondents $(56 \%)$ also received guidance from librarians, while (23\%) acquired the necessary skills via trials and errors (self taught) (Table 2).

Regarding benefits gained from using the electronic information, $67 \%$ of the staff recorded faster access to information, $62 \%$ stated that they allowed a wider range of information, $47 \%$ found it easier access to information and only $32 \%$ felt that the main benefit of electronic resources was to be access to current up-to-date information (Table 3).

Regarding the question about the main barriers of using electronic resources: time consuming and lack of retrieval skills of information were the most important barriers (60\% and 57\% respectively) (Table 4).

Most of the respondents (56\%) stated that they strongly disagreed with the statement of avoiding electronic sources due to inability to use it versus $33 \%$ who 
strongly agreed with it. The difference was statistically significant $(\mathrm{P}<0.05)$. Also, the majority of the respondents (62\%) disagreed with the statement of inability to acquire any significant information from the internet versus those who strongly agreed $(20 \%)$ with statistically significant difference $(\mathrm{P}<0.05)$. It was also detected that $42 \%$ of the respondents declared that their work would suffer without the use of electronic resources versus $41 \%$ who had not been convinced of this statement with no statistically significant difference $(\mathrm{P}>$ 0.05) (Table 5).

Table (1): Percentage distribution of the staff according to the most popular electronic resources used.

\begin{tabular}{|c|c|}
\hline Electronic Resources & Percentage $(\mathbf{n}=\mathbf{1 0 0})$ \\
\hline CD-Roms & 72 \\
Internet & 63 \\
Electronic journals & 27 \\
\hline
\end{tabular}

Table (2): Percentage distribution of the staff according to how they learned to use the electronic resources.

\begin{tabular}{|c|c|}
\hline Methods of learning & Percentage $\quad(\mathbf{n}=\mathbf{1 0 0})$ \\
\hline Guidance from other peers & 72 \\
Courses offered by university or college & 61 \\
Guidance from librarians & 56 \\
External courses & 25 \\
Self taught (trial and error) & 23 \\
\hline
\end{tabular}

Table (3): Percentage distribution of the staff according to their feel about the benefits of using electronic resources.

\begin{tabular}{|c|c|}
\hline Benefits & Percentage $\quad(\mathbf{n}=\mathbf{1 0 0})$ \\
\hline Faster access to information & 67 \\
Access to a wider range of information & 62 \\
Easier access to information & 47 \\
Access to up-to-date information & 32 \\
\hline
\end{tabular}

Table (4): Percentage distribution of the staff according to their feel about the barriers of using electronic resources.

\begin{tabular}{|c|c|}
\hline Barriers & Percentage $\quad(\mathbf{n}=\mathbf{1 0 0})$ \\
\hline Time consuming & 60 \\
Lack of retrieval skills of information & 57 \\
Too much information retrieved & 41 \\
Lack of computer availability & 37 \\
\hline
\end{tabular}


Table (5): Percentage distribution of the staff according to their attitude towards some statements concerning the use of electronic resources of information.

\begin{tabular}{|c|c|c|c|c|}
\hline \multirow{2}{*}{ Statements } & \multicolumn{3}{|c|}{ Attitude of the staff (n = 100) } \\
\cline { 2 - 5 } & $\begin{array}{c}\text { S.A*/ } \\
\text { Agree } \\
(\mathbf{\%})\end{array}$ & $\begin{array}{c}\text { S.D*/ } \\
\text { Disagree } \\
(\%)\end{array}$ & $\begin{array}{c}\text { I Don't } \\
\text { Know } \\
(\%)\end{array}$ & P-value** \\
\hline $\begin{array}{c}\text { Avoiding electronic sources due to inability to use } \\
\text { them }\end{array}$ & 33 & 56 & 11 & $\mathrm{P}<0.05$ \\
$\begin{array}{c}\text { Inability to acquire any significant information } \\
\text { from the internet }\end{array}$ & 20 & 62 & 18 & $\mathrm{P}<0.05$ \\
$\begin{array}{c}\text { The work would suffer without using electronic } \\
\text { sources }\end{array}$ & 42 & 41 & 17 & $\mathrm{P}>0.05$ \\
\hline
\end{tabular}

*S.A. = Strongly agree $\quad *$ S.D. $=$ Strongly disagree

**The statistical test used is $\mathrm{x}^{2}$

\section{Discussion}

The results of this study showed that the most popular electronic resources used by medical staff were CD-Roms and internet as $(72 \%$ and $63 \%)$ respectively. This was in correspond-ence with Allen (1989) who looked at number of studies concerning data base of electronic resources and found that CD-Roms were the most common type used of electronic sources of information and could be utilized without prior knowledge or training.

Regarding the main benefits obtained by using these resources, the higher percentages of the surveyed staff decided that these resources allowed a faster access and a wider range of information besides its easiness. This came in complete agreement with Blum (1986), Day et al. (1990) and Schultz \& Saloman (1990) who all showed in their studies that $83 \%$ of the surveyed users felt that using these resources saved their time and found them relatively easy to use.

Limited time and lack of effective information retrieval skills were found in our study to be the main obstacles facing $60 \%$ and $57 \%$ respectively of the medical staff in using these resources. Van der lei et al. (1993) agreed with this point and suggested more effective search tools with improving information retrieval skills and the knowledge of the most useful data base, so time spent in using these resources may be reduced.

In our study, most of responders $(56 \%)$ refused the statement supposing that "using of electronic information resources by the staff was usually avoided due to inability to use them" and more positively $62 \%$ of the staff denied that they could not obtain any information from the internet, while $(42 \%)$ declared that their work would suffer without using these resources. All these results showed that obstacles of use detected before did not contradict with the ability of the staff to use these resources, and they had a reasonable level of retrieval skills of information and this is exactly what was reached by other studies as Prophy (1993) and Simborg (1994) who also emphasized the importance of utilizing these resources in conducting researches.

Views of staff interviewed suggested the following approaches that may support staff use of electronic resources: conducting in-depth studies in this field is needed, ensuring there are sufficient computer network available at the university or college and information retrieval skills training to be embedded in the curriculum, undertaken at an appropriate time and supported by the academic staff. 


\section{References}

1. Allen, A. (1989): Electronic information effect on health care programs. Oxford University Press.

2. Bawden, D. (1990): User-oriented evaluation of information systems and servicesAldershot: Gower.

3. Blandy, S.G. and Libutti, P.O.B (1995): As the cursor blinks: electronic scholarship and undergraduates in the library. Library trends, 44(2): 279-305.

4. Blum, B.L. (1986): Information system for patient care. New York, Springer Verleg, 16: 70-81.

5. Brophy, P. (1993): Networking in British academic libraries. British Journal of Academic Librarianship, 8(1): 49-60.

6. Day, J.; Edwards, G.; Walton, G.; Curry, S.; Bent, M. and Jackson, M. (1990): Higher education, teaching learning and the electronic library: a review of the literature for the IMPEL2 project: monitoring organizational and culture change. New Review of Academic Librarianship, 12: 131-208.

7. Dutton, B.G. (1990): An introduction to end-user searching. In: By South, P.T. (ed.) End user searching: the effective gateway to published information. London: Aslib, L18.

8. Schultz, K. and Saloman, K. (1990): End users respond to CD-Rom.Library Journal: 56-57.

9. Shortliffe, E.H. and Perreault, L.E. (1996): Computer application in health care. Addison-Wesley; 12: 1-4.

10. Simborg, D.W. (1994): Networking and medical information system. Journal of Medical Systems.

11. Van der lei, Duisterhout, J.S. and Westerhaf, H. (1993): The introduction of computer-based patient care in the Netherlands. Ann. Intern. Med., 119: 1036-1041. 


\title{
ادراك أعضاء هيئة التدريس بكلية الطب نحو استخدام

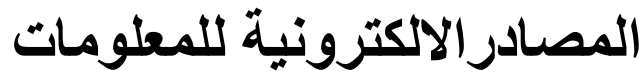

\author{
أيمن سبا عبد الهادى \\ قسم طب المجتمع بكلية الطب - جامعة الأزهر لهرئ الهرع أسيوط
}

خلال السنو ات القليلة الماضية حدثت زيادة غير مسبوقة فيى حجم المعلومـات

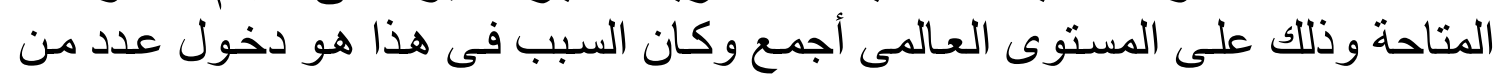

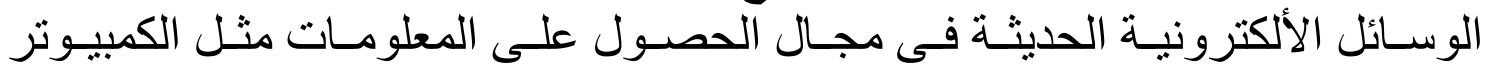

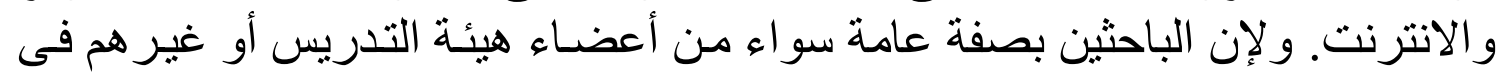

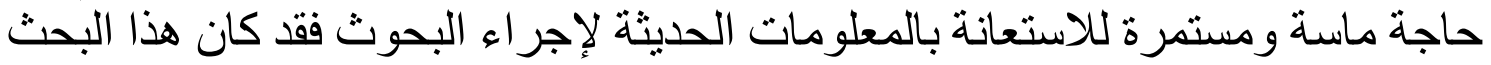

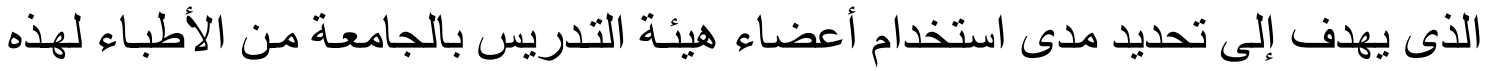
الوسائل الحديثة وكثف اتجاهاتهم نحو بعض القضاء القضايا المتعلقة باستخدامها.

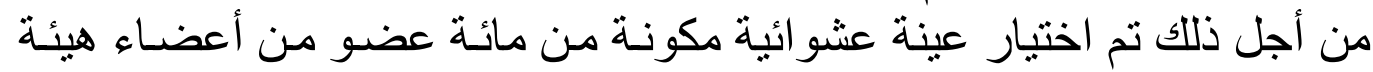

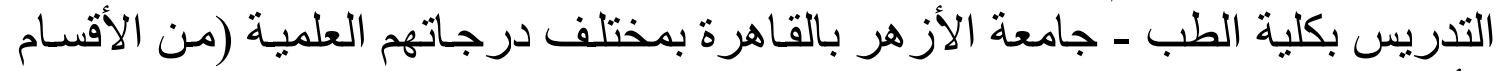

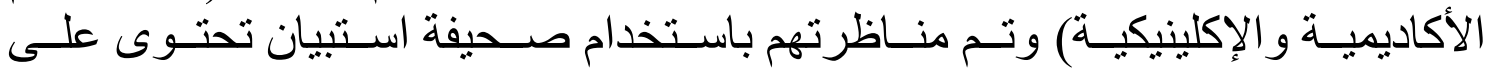
المتغير ات المطلوبة.

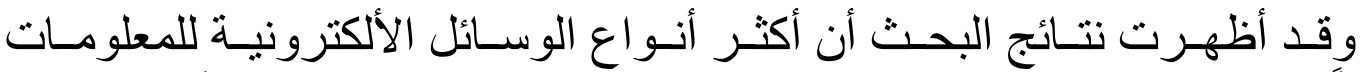

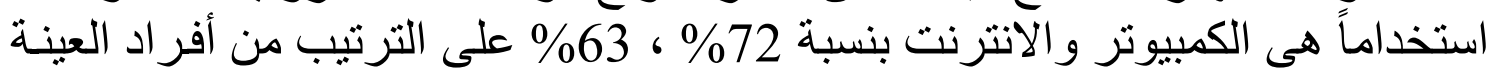

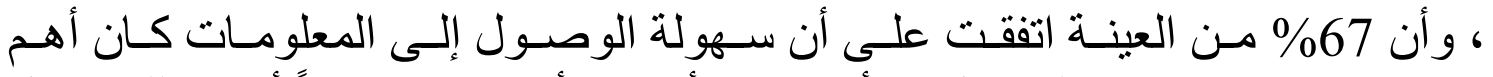

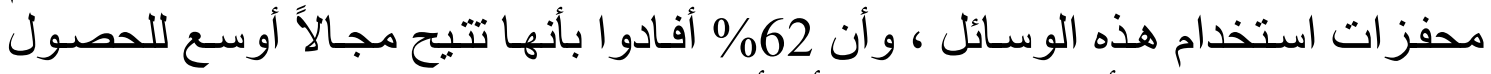

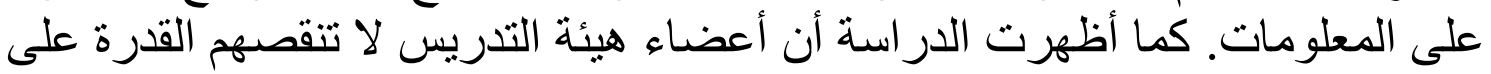

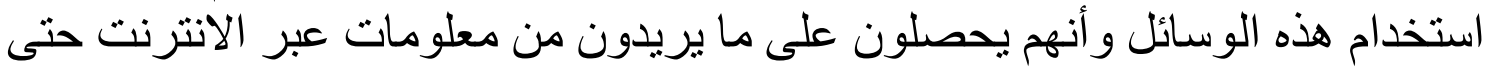

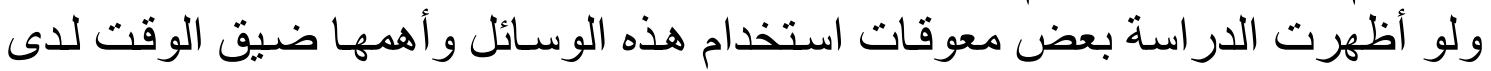

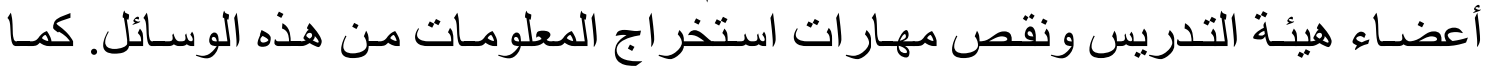

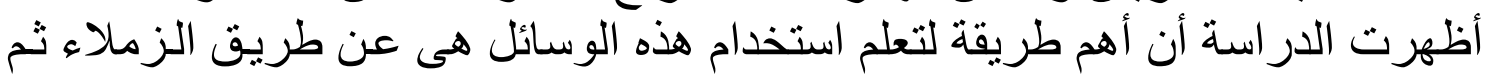
عن طريق البرامج التى توفر أهما الجامعة.

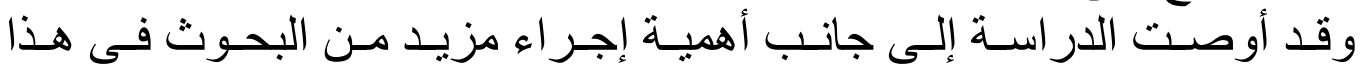

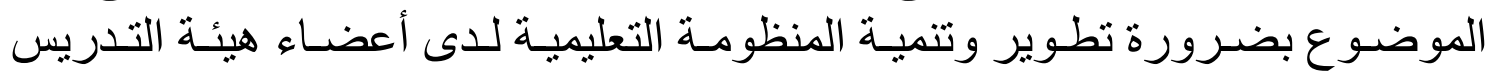

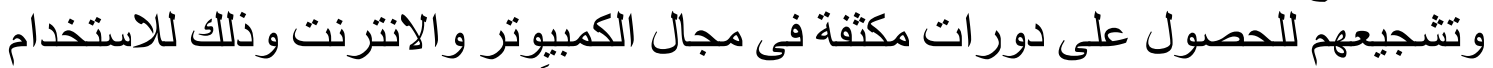

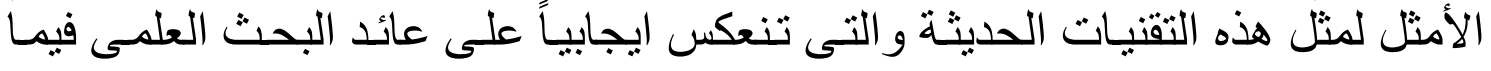
يختص بالتطبيق وتقديم الخدمات الصحية. 